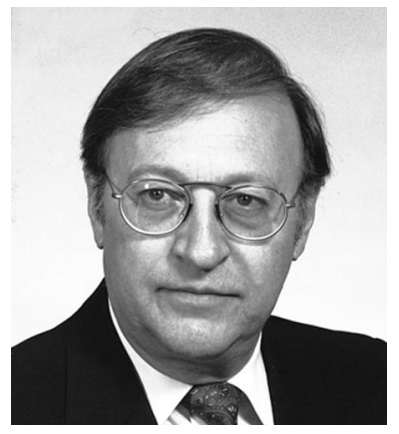

\section{It has been a marvelous experience!}

It is with a certain sadness that I am writing this editorial. Over the last 12 months, I have very much enjoyed finding topics to write about that would keep me in touch with the readers of Optical Engineering. The great people who make this publication possible elevate this journal to a level comparable to any other in its field worldwide. You can be assured that I have tried very hard to foster some exchange and discussion by taking on controversial subjects in my editorials. Unfortunately, I never received long replies to my views such that I could publish them as part of an editorial.

I would like first to thank the readers who take the time and make the effort to contact me to express their agreements and disagreements with the opinions I have been writing in these pages. I was greatly honored to receive those comments and suggestions, and I will miss them. I hope that those who wrote to me will recognize themselves and I hope that they accept my thanks.

I would also like to thank the increasing group of scientists who choose Optical Engineering as the peerreviewed journal in which they publish their most important results. Thanks to your involvement, Optical Engineering is getting better and better every month.

Another group of devoted people must also get my thanks: the editorial team. Although some associate editors did step down during the present year for various reasons, I would like to thank all of them for their profound involvement and their professionalism in the treatment given to the papers I assigned to them. As information to our readers, I would like to underline the constant effort of our Editorial Board to keep the process as short as possible, as well as its hard work to find reviewers who will spend time to do serious reviews of papers that are sent to them. I will not list the associate editors here since I do not want to make any mistakes by omission. However, if you look at the masthead in each issue, you will see that many are involved in the peer-review process. Their diligence allows Optical Engineering to have a better impact factor; the impact of Optical Engineering has greatly improved in recent years.

Recently we announced a new rapid publication feature in OE called Optical Engineering Letters, an initiative of SPIE President and returning OE Editor Don O'Shea. We have already received some papers that are under review and we encourage our readers to use this fast track for publishing brief letters describing important and new results that cannot suffer delays; please advise your colleagues to do the same. The review process in this case is tough, but fair and faster than the normal review process. Please have a look at the August issue in which this new initiative was very well explained.

Finally, I do not want to leave the editorial board of this journal without noting the importance of the SPIE team that works very hard behind us, pushes us on, and in fact supervises the busy people that we are and prevents us from forgetting any important issues. Many thanks to Karolyn Labes, Anne Munger, Rita Davis, Michelle Luff, Chris Engebo, and Eric Pepper for your support and help during this year 2000. I will never forget it. It has been a privilege for me to have the chance to work with you and I just hope that you did not find my French English writing too difficult; you corrected it in a very nice way.

To all of you I extend my sincere thanks and I look forward to being able to serve you again in the near future.

My sincere welcome back to Don O'Shea. 